\title{
Expression of c-kit gene products in known cellular targets of $W$ mutations in normal and $W$ mutant mice-evidence for an impaired c-kit kinase in mutant mice
}

\author{
Karl Nocka, ${ }^{1}$ Sadhan Majumder, ${ }^{1}$ Benoit Chabot, ${ }^{2}$ Prabir Ray, ${ }^{1}$ Michelle Cervone, ${ }^{1}$ Alan Bernstein, ${ }^{2}$ \\ and Peter Besmer ${ }^{1}$ \\ ${ }^{1}$ Molecular Biology Program, Sloan Kettering Institute and Cornell University Graduate School of Medical Sciences, New \\ York, New York 10021; 2Division of Molecular and Developmental Biology, Mount Sinai Hospital Research Institute, \\ Toronto, Ontario M5G 1X5, Canada
}

\begin{abstract}
The proto-oncogene c-kit, a transmembrane tyrosine protein kinase receptor for an unknown ligand, was shown recently to map to the dominant white spotting locus $(W)$ of the mouse. Mutations at the $W$ locus affect various aspects of hematopoiesis, as well as the proliferation and/or migration of primordial germ cells and melanoblasts during development. Here, we show that c-kit is expressed in tissues known to be affected by $W$ mutations in fetal and adult erythropoietic tissues, mast cells, and neural-crest-derived melanocytes. We demonstrate that the c-kit associated tyrosine-specific protein kinase is functionally impaired in $W / W^{V}$ mast cells, thus providing a molecular basis for understanding the developmental defects that result from these mutations.
\end{abstract}

[Key Words: c-kit; kinase; mutation; spotting $W$ locus]

Received February 1, 1989; revised version accepted March 20, 1989.

Mutations at the murine dominant-white spotting locus $(W)$ affect various aspects of hematopoiesis and the proliferation and/or migration of primordial germ cells and melanoblasts during embryogenesis (Russell 1979; Silvers 1979|. Many independent mutations are known at the $W$ locus; they are semidominant mutations, and the different alleles vary in their degree of severity and their effect on the different cell lineages (Russell 1979; Geissler et al. 1981). For example, mice homozygous for the $W$ allele die neonatally or in utero of severe macrocytic anemia, display extensive white spotting, and are sterile (Little 1915; deAeberle 1927). Heterozygous W/ + mice have some white spotting, are fertile, and have normal blood parameters. In contrast, mice carrying the $W^{V}$ allele when heterozygous have a mild anemia, minor spotting, and a diluted coat color, and they are fertile; when homozygous, they are viable. The large number of known, distinct $W$ mutations provides a unique opportunity to characterize both the consequences of these mutations on different tissues and the molecular basis for the developmental defects that result from these mutations.

During normal embryogenesis, primordial germ cells migrate from the yolk sac splanchnopleure to the germinal ridges and melanoblasts migrate from the neural crest to the periphery. Both of these migratory pathways are affected by $W$ mutations (Mintz and Russell 1957; Mayer and Green 1968). During early development, the blood islands in the yolk sac are a major site of hematopoiesis. Subsequently, at day $10-11$ of gestation, hematopoietic stem cells migrate to the fetal liver and then to the spleen and the bone marrow, the sites of active adult hematopoiesis (Moore and Metcalf 1970). The hematopoietic defect in $W$ mice is first apparent in the blood islands of the embryonic yolk sac and then persists as hematopoietic stem cells migrate to the fetal liver and to the sites of neonatal and adult hematopoiesis. The defect exerted by $W$ mutations is intrinsic to hematopoietic cells; in syngeneic transplantation experiments the macrocytic anemia in $W$ mice can be cured because of a proliferative advantage of donor marrow over mutant marrow (Russell and Bernstein 1968; Harrison 1980; Barker and McFarland 1988). The hematopoietic microenvironment in these animals is unaffected and able to support hematopoiesis.

The hematopoietic cells that are affected by the $W$ mutations include cells within the stem cell hierarchy (CFU-S) (McCulloch et al. 1964), cells of the erythroid cell lineage (Gregory and Eaves 1978), as well as mast cells (Kitamura and Go 1978). The elucidation of the 
mechanism by which $W$ mutations exert their pleiotropic effects on hematopoiesis and embryonic development is of great importance for understanding these processes. An important step toward this goal was the recent identification of the gene encoded at the $W$ locus. By using genetic linkage analysis, we have mapped the proto-oncogene c-kit to the $W$ locus on mouse chromosome 5 (Chabot et al. 1988), raising the possibility that the $W$ locus is allelic with c-kit. In support of this hypothesis, Geissler and co-workers (1988) subsequently showed that the c-kit gene is rearranged in two different $W$ mutants.

The proto-oncogene c-kit is the cellular homolog of $\mathrm{v}-\mathrm{kit}$, the oncogene of an acute transforming feline retrovirus, HZ4-FeSV, which was isolated from a feline leukemia virus-associated feline fibrosarcoma (Besmer et al. 1986). The oncogene $\mathrm{v}$-kit encodes the catalytic domain of a tyrosine-specific protein kinase that is most closely related to the tyrosine kinases of the receptors for platelet-derived growth factor (PDGF) and colony-stimulating factor 1 (CSF- 1 ), is expressed as an $80 \mathrm{kD}^{\text {gag-kit }} \mathrm{fu}-$ sion protein in HZ4-FeSV-infected cells, and exhibits tyrosine-specific protein kinase activity (S. Majumder and P. Besmer, unpubl.). The characterization of cDNAs of the proto-oncogene c-kit of mouse and human origin predicted that c-kit encodes a transmembrane kinase similar to CSF-1R and PDGFR (Qiu et al. 1988; Yarden et al. 1987). In agreement with this prediction, a $145-\mathrm{kD}$ tyrosine-specific transmembrane kinase has been identified and characterized in brain tissue extracts and in a human glioblastoma cell line (Yarden et al. 1987; Majumder et al. 1988). The unique features of c-kit, CSF-1R, and PDGFR are an extracellular domain that is made up of five immunoglobulin-like repeats, indicating that these receptors are members of the immunoglobulin superfamily and a tyrosine kinase that is split into two domains by an insert sequence of variable length (Qiu et al. 1988). The c-kit ${ }^{W}$ protein is probably the receptor for a ligand (as yet unidentified) consistent with an earlier conjecture that the $W$ locus encodes a cell-surface receptor that functions in cell-cell interactions during development and hematopoiesis (Russell 1979).

The identification of tissues and cells that express c-kit during development and in the adult animal is of great importance in understanding the normal function of c-kit. Because of the intrinsic nature of the $W$ mutations, it is quite likely that cellular targets affected by $W$ mutations express c-kit gene products, although c-kit expression may also occur in cell types that are not known to be affected by $W$ mutations. To gain a deeper understanding of the normal function of c-kit and of how $W$ mutations influence $c-k i t$ function, we have analyzed c-kit expression in embryonic and adult hematopoietic tissues in normal mice and in $W / W$ and $W / W^{V}$ mice, in cell lines, as well as in adult mouse tissues. We show that the c-kit gene product is expressed in fetal and adult erythropoietic tissues, mast cells, and neuralcrest-derived melanocytes. To determine the molecular basis of how $W$ mutations exert their pleiotropic effects, we have characterized functional properties of the $c-k i t$ gene products in $W$ mutant animals and we show that $\mathrm{c}-\mathrm{kit}^{\mathrm{W}}$ mutations can impair the tyrosine-specific kinase activity of the c-kit protein.

\section{Results}

Expression of c-kit RNA transcripts in adult and fetal hematopoietic tissues

To identify sites where c-kit may function in vivo, the expression of c-kit RNA was investigated first in tissues from adult mice. For this purpose, RNA was prepared from various tissues and then analyzed by blot hybridization (Fig. 1). In normal adult animals, expression was observed in placenta, brain, ovary, bone marrow, spleen, testis (see also Fig. 5A), and lung. The highest level of c-kit RNA was found in placenta from pregnant females at 18 days of gestation. In all samples, a 5.5-kb RNA species was seen, as reported earlier (Yarden et al. 1987; Qiu et al. 1988). In addition, in samples with high levels of c-kit RNA expression such as the placenta, RNA species of $\sim 8$ and $11 \mathrm{~kb}$ are seen, which may represent partially processed c-kit transcription products.

Because of the known effect of $W$ mutations on erythropoiesis and on hemtopoietic stem cells, the expression of c-kit RNA was examined in prenatal hematopoietic tissues. The fetal liver is the major site of hematopoiesis from days 12 to 18 of fetal development, whereas the bone marrow is the predominant site of hematopoiesis in the adult animal. Total cellular RNA was prepared from day-13 and day-14 fetal liver and analyzed with Northern blots. Expression of c-kit RNA was detected in fetal livers at levels higher than in adult bone marrow (Fig. 1, lanes 5, 11, and 12), which is in contrast to the low level of c-kit RNA in adult liver (Fig. 1, lane 13). The pattern of expression of c-kit in fetal and adult liver correlates with the time at which the liver is the major hematopoietic organ. In day- 14 fetal liver, $>90 \%$ of the nucleated cells are of the erythroid lineage. The correlation of c-kit expression with tissues involved in erythropoiesis was confirmed by analysis of spleens from mice infected with Friend murine leukemia virus (F-MuLV). The enlarged spleens from F-MuLV-infected animals are highly enriched for erythroblasts. Expression of c-kit RNA in F-MuLV spleens was found to be increased three to four times over the low levels observed in spleens from normal adult animals (not shown).

\section{Survey of c-kit expression in hematopoietic cell lines}

A number of hematopoietic and nonhematopoietic cell lines were then analyzed for expression of c-kit. At first, cell lines corresponding to cell types known to be affected by mutations at the $W$ locus in vivo were selected for analysis. Total RNA from the mast cell lines MC, an IL-3-dependent line derived from a long-term bone marrow culture, and P815, an IL-3-independent mastocytoma line (not shown), were found to contain high levels of c-kit RNA $>20$ times the level observed in placenta) (Fig. 2). Expression at lower levels was observed in erythroleukemic cell lines derived from the spleens of mice infected with Friend spleen focus-forming virus 
Nocka et al.

Figure 1. Expression of c-kit RNA transcripts in normal mouse tissues. RNA was prepared from adult brain, testis, ovary, lung, bone marrow (B.M.), spleen, thymus, Peyer's patches, intestine, fetal liver (FL) at 13 and 14 days of gestation, adult liver, muscle, heart, kidney, adrenal gland, and placenta of females at 18 days of gestation of NFS mice and then analyzed by agarose gel electrophoresis and blot hybridization. Total cellular RNA (15 $\mu \mathrm{g}$ ) was used in each lane. Hybridization was done with a $c-k i t$ cDNA probe. Ethidium bromide staining of the gel is shown below to indicate equal loading. Migration of $28 \mathrm{~S}$ and 18S RNA is indicated.

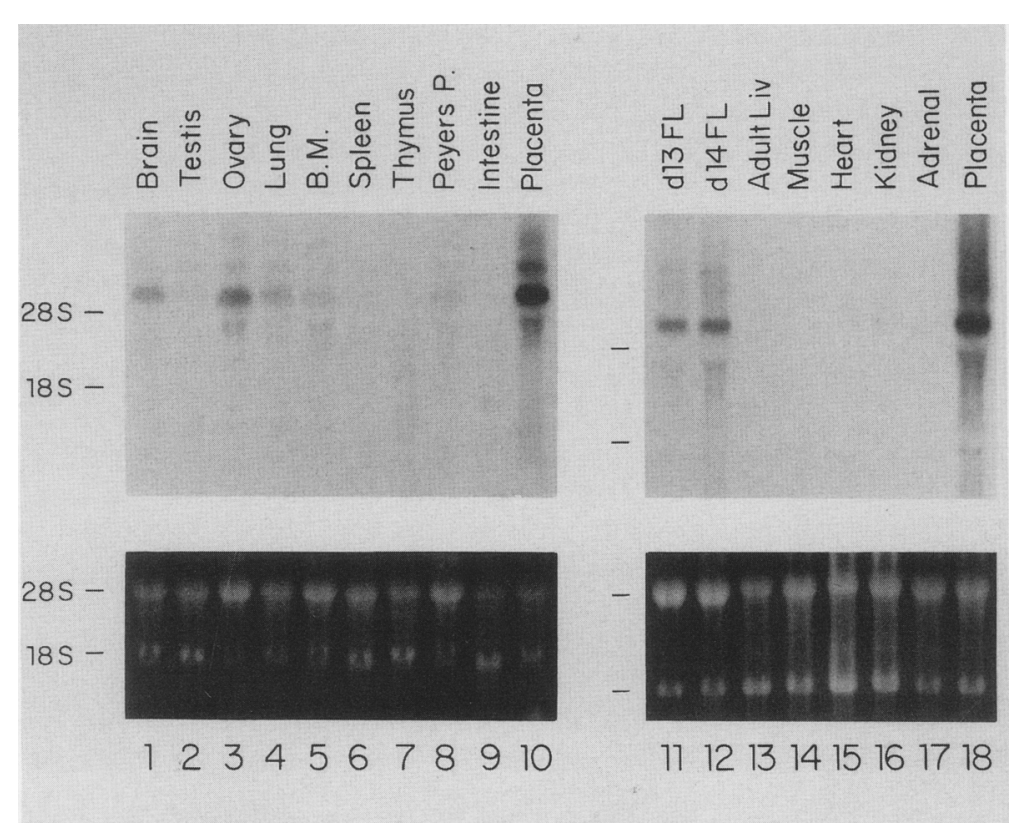

c-kit protein products in mast cells and melanocytes

(SFFV) (DP15, DP27, DP28, and lower levels in DP20). A very low level of or no c-kit expression was observed in the erythroleukemic line $\mathrm{CB} 7$ derived from the spleen of a BALB/c mouse neonatally infected with Friend helper virus (F-MuLV) and in the MEL cell line. A barely detectable level of $c-k i t$ expression was observed in the IL-3dependent pluripotential stem cell line FDCP-mix clone A4, which was obtained from a long-term bone marrow culture infected with an MuLV vector containing the oncogene v-src. No expression of c-kit RNA was observed in the myelomonocytic cell lines WEHI-3B D + or D - (not shown), in the myeloid cell lines M1 and $32 \mathrm{D}$, in a number of monocytic/macrophage cell lines from control or $\gamma$-interferon-stimulated cultures (not shown), in lymphoid cell lines of the T-cell lineage, CTLL, EL-4, AKR thymoma-derived CK4, CK6, 69L1, or a panel of Abelson-MuLV-transformed immature and mature B cell lines. Taken together, these results indicate expression of c-kit in cell lines corresponding to cell types known to be affected by $W$ mutations, namely mast cells and cells of the erythroid lineage. Conversely, c-kit expression is not detectable in hematopoietic cell lineages that do not appear to be targets for $W$ mutations.

\section{c-kit RNA transcripts in neural-crest-derived cells}

A major hallmark of mice with a mutation at the $W$ locus is a defect in pigmentation. To evaluate the role of c-kit in melanogenesis we have analyzed RNA prepared from melanoma and melanocyte cell lines. c-kit RNA expression at levels similar to that observed in placenta was seen in a TPA-dependent melanocyte cell line derived from normal newborn mice (Tamura et al. 1987). In addition, little or no c-kit RNA was seen in the amelanotic Cloudman melanoma or the B16 melanoma (not shown). These results indicated expression of c-kit RNA in terminally differentiated pigment cells.
By using the immune complex kinase procedure, we have previously identified a gp $145-\mathrm{kD}$ c-kit protein product in brain tissue and then characterized its autophosphorylating activity. It was of great interest to characterize the c-kit protein products in bone-marrow-derived mast cells (see below), the mast cell line MC, the melanocyte cell line, and NIH cells expressing the brain $c-k i t$ cDNA as part of a retroviral expression vector (NHck) to identify structural differences of the c-kit protein products in the three cell types. Cells were labeled with ${ }^{35}$ S]methionine, and an immunoprecipitation analysis was carried out using a v-kit-specific rabbit antiserum. SDS/PAGE analysis of immunoprecipitates obtained from extracts of $\left.{ }^{35} S\right]$ methionine-labeled cells is shown in Figure 3. Two bands, each corresponding to proteins containing kit determinants of 145 and $124 \mathrm{kD}$, 160 and $124 \mathrm{kD}$, and 165 and $124 \mathrm{kD}$, were observed in NHck cells, mast cells, and the melanocyte cell line, respectively. The 145-, 160-, and 165-kD bands very likely correspond to fully processed neuraminidase-sensitive glycoproteins, and the $124-\mathrm{kD}$ bands, by analogy, to partially processed glycoproteins containing high mannose structures (Majumder et al. 1988). To determine whether the variable size of these glycoproteins was the result of differential glycosylations or was due to an altered primary amino acid sequence, the c-kit proteins from tunicamycin-treated cells were analyzed. Indistinguishable bands corresponding to proteins of $106 \mathrm{kD}$ were obtained from tunicamycin-treated NHck and mast cells (Fig. 4, lanes 2 and 4), as well as from the melanocyte cell line (not shown). These results then indicate that the variable size of the c-kit protein products in fibroblasts, mast cells, and melanocytes is the result of differences in post-translational modifications and, most likely, is due to variable glycosylations of the c-kit pro- 


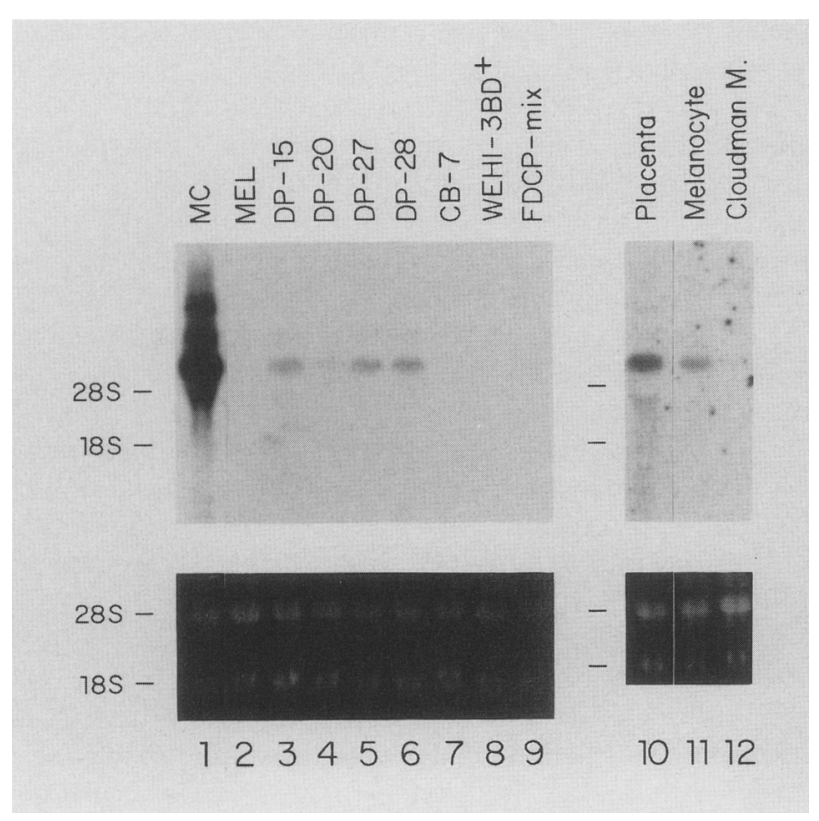

Figure 2. Expression of c-kit RNA transcripts in hematopoietic cell lines and in melanocyte and melanoma cell lines. Total cellular RNA was prepared from the IL-3-dependent murine mast cell line MC (lane 1); the erythroid cell lines: MEL (lane 2), DP15 (lane 3), DP20 (lane 4), DP27 (lane 5), DP28 (lane 6), and CB7 (lane 7); myelomonocytic WEHI-3B D ${ }^{+}$cells (lane 8), and pluripotential FDCP-mix clone A4 cells (lane 9), as well as from the melanocyte cell line ME (lane 11) and Cloudman melanoma cells (lane 12). RNA from day-18 placental tissue was used as a positive control. Total cellular RNA was loaded in lanes 1-9 (15 $\mu \mathrm{g})$ and in lanes 10-12 (15 $\mu \mathrm{g})$. Hybridization was done with the c-kit cDNA probe. Ethidium bromide staining of the gels is shown below. Migration of $28 \mathrm{~S}$ and $18 \mathrm{~S}$ RNA is indicated.

teins. The observation that the three cell lines synthesize an indistinguishable primary translation product of $106 \mathrm{kD}$ is in agreement with the observation that all cell lines and tissues that express c-kit contain the same 5.5kb c-kit RNA transcript.

\section{c-kit expression in $\mathrm{W} / \mathrm{W}$ fetal liver}

The observations described above indicate a tight correlation between those cell types known to be affected by mutation at the $W$ locus and c-kit expression. It was of interest to analyze the effect of mutation at the $W$ locus on c-kit expression. For these experiments, we chose to compare c-kit expression in the livers of normal $1+1+1$ and mutant $(W / W)$ embryos at day 14 of gestation. Mice homozygous for the original $W$ mutant allele die late in gestation or shortly after birth, presumably because of severe anemia. Fetal livers were obtained by breeding $W /+\times W /+$ animals to generate offspring that were either $+/+, W / t$, or $W / W$ in genotype. The $W / W$ homozygotes could be distinguished easily from their $+/+$ or $W /+$ littermates on the basis of their smaller size and the pale color of their livers. In one litter, there were three fetuses $(7,8$, and 9$)$ that were judged to be $W / W$ homozygotes based on the above criteria. No c-kit RNA was detected in the fetal livers of these animals (Fig. 4; liver 7 is not shown). In contrast, the other seven fetal livers, which were judged by their red colors to be $+1+$ or $W /+$, expressed high levels of c-kit transcripts (Fig. 4; liver 5 is not shown).

There are two explanations for the virtually undetectable levels of c-kit RNA in day-14 fetal livers from $W / W$ homozygotes. First, it is possible that the $W$ mutation, as has been suggested for the $W^{44}$ allele (Geissler et al. 1988), has a primary effect on transcription. Alternatively, the absence of detectable levels of c-kit RNA in $W / W$ fetal livers might be the result of a severe reduction in the number of cells in the fetal liver that express $\mathrm{c}-\mathrm{kit}$ as a result of the functional inactivation of the c-kit gene product. To distinguish between these possibilities, we examined c-kit expression in the brain and placenta of the same fetuses as described above. The levels of c-kit RNA in $W / W$ placentas was approximately onethird of that observed in normal $(+/+$ or $W / W)$ placentas, whereas c-kit transcripts were reduced approximately three- to fourfold in the brain in $W / W$ fetuses (data not shown). We consistently observed a small, but readily apparent, reduction in the size of the c-kit tran-

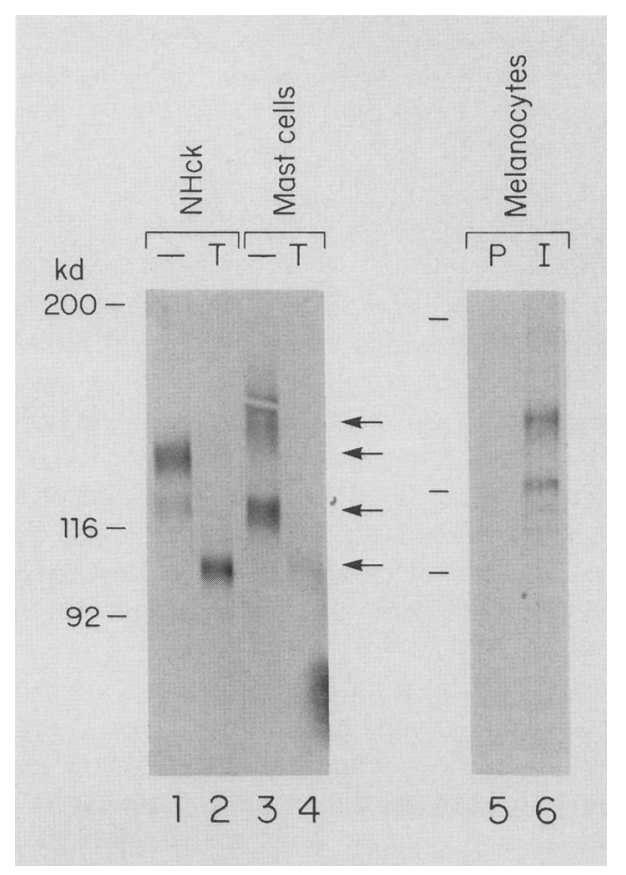

Figure 3. Analysis of the c-kit protein products in mast cells and melanocytes. NIH cells expressing a c-kit-expressing retroviral vector (NHck, lanes 1 and 2) and tissue-culture mast cells obtained from $\mathrm{WBB}^{6}+1+$ bone marrow were labeled for $5 \mathrm{hr}$ with $\left.{ }^{35} S\right]$ methionine in the absence $(-)$ (lanes 1 and 3$)$ and presence of $8 \mu \mathrm{g} / \mathrm{ml}$ of tunicamycin (T) (lanes 2 and 4). Protein lysates were precipitated with kit antiserum and analyzed by SDS/PAGE and autoradiography. The melanocytes (ME cells) were labeled for $2 \mathrm{hr}$ with $\left.{ }^{35} \mathrm{~S}\right]$ methionine and immunoprecipitated with kit antiserum (I) and preimmune serum $(\mathrm{P})$ and analyzed by SDS/PAGE and autoradiography. Arrows indicate the relative mobilities of c-kit protein products. Protein size markers are indicated in kilodaltons. 


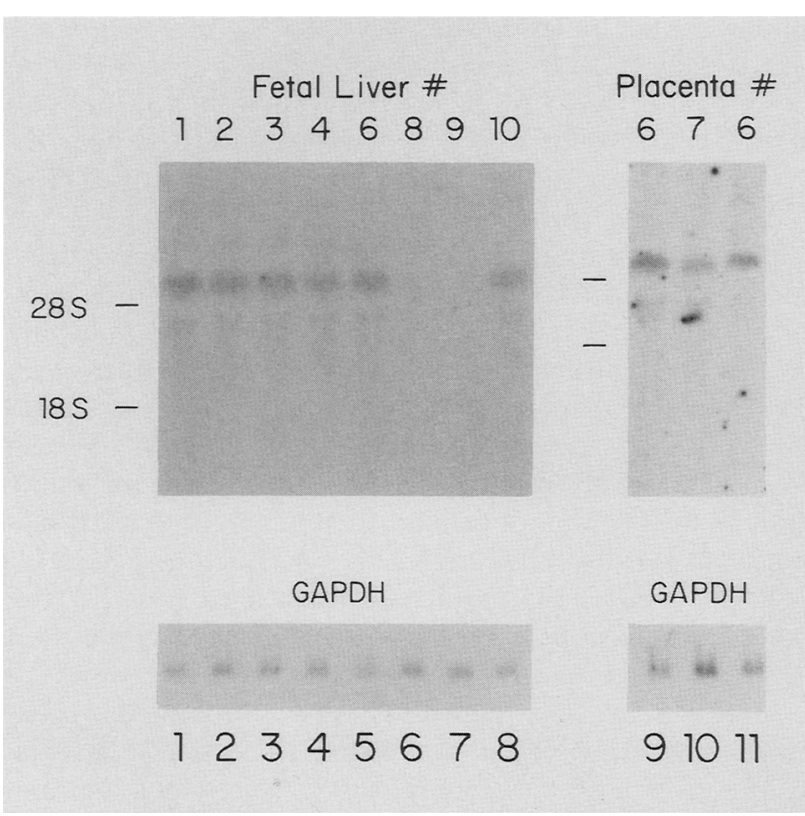

Figure 4. Expression of c-kit RNA transcripts in $W / W$ fetal tissues. RNA was prepared from the liver and the corresponding placenta of ten 14-day-old embryos obtained by breeding $W /+\times W /+$ mice and analyzed by blot hybridization. Total cellular RNA (15 $\mu \mathrm{g}$ ) was used in each lane, and hybridization was done with c-kit cDNA probe. Hybridization with a GAPDH probe is shown below to indicate equal loading. The $W / W$ placenta sample (lane 10 ) was flanked by the same $+1+$ placenta sample (lanes 9 and 11) to accentuate the size difference. Migration of $28 \mathrm{~S}$ and $18 \mathrm{~S}$ ribosomal RNA is indicated.

script in $W / W$ placentas (Fig. 4, lane 10) and fetal brains (not shown) when compared to the size of the c-kit transcript from their normal littermates (Fig. 4, lanes 9 and 11). These results are in agreement with the notion that the marked reduction in the level of c-kit RNA in $W / W$ fetal liver is primarily due to the absence of c-kit-expressing cells, in addition to a minor effect on c-kit transcription. The data also suggest that the c-kit transcripts in the placenta are derived from embryonic and not maternal tissue.

\section{Erythroid progenitors in W/W fetal liver}

The data described in the preceding section suggested that the inability to detect c-kit transcripts in $W / W$ fetal liver might be a reflection of the altered cellular composition of day-14 fetal liver in these mutant animals. To test this possibility and also to analyze the spectrum of hematopoietic progenitor cells present in a tissue with diminished c-kit function, we assayed the livers of fetuses derived by mating $\mathrm{W} /+$ heterozygotes for their content of hematopoietic progenitor cells. Fetuses were judged to be homozygous for the $W$ mutation $(W / W)$ by the identical criteria as described above. In addition, in some cases, cells from the fetal livers were inoculated into lethally irradiated recipients to assay for spleen colony-forming cells (CFU-S). Homozygous $W / W$ livers lack detectable numbers of CFU-S, as reported pre- viously for bone marrow cell population from adult $W / W^{V}$ animals (McCulloch et al. 1964).

Three classes of committed progenitor cells were examined from these fetuses: granulocyte-macrophage precursors (GM-CFC); erythroid burst-forming units (BFU-E); and erythroid colony-forming units (CFU-E). As shown in Table 1, no significant differences were observed in either the number or size of BFU-E or GM-CFC in $W / W$ versus $+1+$ or $W /+$ fetal livers, examined on days 14,15 , or 16 of gestation. In contrast, there was a marked reduction in the number of relatively mature CFU-E in $W / W$ fetal livers. This was most evident at day 15 when there was approximately a 30 - to 50 -fold reduction in the number of CFU-E in $W / W$ fetal liver relative to their normal littermates. By day 16 , the reduction in CFU-E was about sevenfold.

We also analyzed the number of these progenitor cells in the livers of fetuses carrying two different mutations at the $W$ locus $\left(W\right.$ and $\left.W^{v}\right)$. Compound $W / W^{v}$ embryos do not die but generate viable but severely anemic animals. Only a slight reduction in the number of BFU-E was observed, whereas there was only a sixfold reduction in the numbers of CFU-E at day 15 /data not shown).

The data in Table 1 are consistent with the conclusion reached above that the absence of detectable c-kit transcripts in $W / W$ fetal livers reflects an alteration in the composition of the fetal livers as a consequence of the $W$ mutation. Furthermore, these results imply that mutation at the c-kit ${ }^{w}$ locus results in a profound depression in the proliferation and/or differentiation of committed erythroid progenitor cells.

\section{$c$-kit $R N A$ transcripts and protein tyrosine kinase activity in $+1+$ and $\mathrm{W} / \mathrm{W}^{V}$ mice}

To investigate the effect of the $W$ mutations in $W / W^{V}$ mice, we undertook a comparative analysis of the c-kit RNA transcripts and of the c-kit protein products and associated protein kinase activity in brain and mast cells from $+l+$ and $W / W^{v}$ mice. Homogeneous populations of tissue-culture mast cells were prepared from bone marrow of $+1+$ and $W / W^{V}$ mice in the presence of con-

Table 1. Hematopoietic progenitor cells in normal and W/W mutant fetal livers

\begin{tabular}{llrrrr}
\hline $\begin{array}{l}\text { Experi- } \\
\text { ment }\end{array}$ & Genotype $^{a}$ & Day & CFU-E & BFU-E & GM-CFC \\
\hline 1 & $+l+, W /+(7)$ & 14 & 565 & 65 & 125 \\
& $W / W(2)$ & 14 & 20 & 78 & 142 \\
2 & $+l+, W /+(6)$ & 15 & 944 & 29 & 102 \\
& $W / W(2)$ & 15 & 41 & 20 & 131 \\
3 & $+/+, W /+(4)$ & 16 & 842 & 23 & 82 \\
& $W / W(2)$ & 16 & 161 & 29 & 100 \\
\hline
\end{tabular}

Single cell suspensions were prepared from fetal livers at the days indicated. The number of CFU-E, BFU-E, and GM-CFC were scored on days $2-3,8$, and 9 , respectively. All values are expressed per $10^{5}$ nucleated fetal liver cells.

a The numbers in parentheses denote the number of individual fetuses assayed. 
ditioned medium from WEHI 3B cells. Histological examination of the $+/+$ and $W / W^{V}$ mast cells with Wright's stain in both samples showed granules characteristic of mast cells (not shown). The analysis of RNA transcripts in brain tissue and in primary mast cells is shown in Figure 5A. No significant difference in expression of the 5.5-kb c-kit RNA transcript was seen in the brain and the mast cell RNAs, indicating that the mutations in the $W / W^{V}$ alleles do not affect c-kit transcription. This result is in contrast to the suppression of $c-k i t$ RNA transcripts in brains of homozygous $W^{44} / W^{44}$ mice (Geissler et al. 1988). The expression of the c-kit proteins in mast cells of $+/+$ and $W / W^{V}$ mice was investigated next to determine whether the $W$ mutations affect the synthesis of the c-kit proteins. SDS/PAGE analysis of immunoprecipitates obtained from extracts of $\left[{ }^{35} \mathrm{~S}\right]$ methionine-labeled mast cells is shown in Figure 5B. Similar amounts of the 160- and 124-kD c-kit glycoproteins were seen in the $+1+$ and the $W / W^{V}$ mast cells (Fig. 5B, lanes 1 and 2). In addition, the 160- and the 124$\mathrm{kD}$ glycoproteins, as well as the $106-\mathrm{kD}$ primary c-kit translation product obtained by tunicamycin treatment of mast cells, are indistinguishable in size in $+1+$ and $W / W^{V}$ mast cells (Fig. $5 B$, lanes $1-4$ ). These results indicate that the c-kit protein products in $+/+$ and $W / W^{V}$ mast cells are expressed at similar levels and have indistinguishable structural characteristics.

To determine whether the c-kit-associated tyrosinespecific protein kinase activity is affected by the $W \mathrm{mu}-$ tation in $W / W^{V}$ mice, immune complex kinase assays were performed. Equal amounts of extract from $+1+$ and $W / W^{V}$ mast cells, as well as a $1: 1$ mixture of the two extracts, were immunoprecipitated by using antikit2 antibody and incubated with $\left[\alpha^{-32} \mathrm{P}\right] \mathrm{ATP}$ and manganese ions in a kinase reaction. SDS/PAGE analysis of the reaction products shown in Figure 5C indicates that the c-kit-associated kinase activity is negligible in $W / W^{V}$ mast cells and $70 \%$ of the expected activity is seen in a mixing experiment. A phosphoamino acid analysis of autophosphorylated $+1+c-k i t$ protein was carried out to establish the specificity of the observed phosphorylation reaction (Fig. $5 \mathrm{C}$ ). The results of these experiments indicate that the c-kit protein in $W / W^{V}$ mast cells has a significantly reduced tyrosine-specific kinase activity. In agreement with this observation, the brain c-kit protein from $W / W^{V}$ mice was found to have a defective kinase activity as well (Fig. 5D, lane 2). Taken together, our results suggest that the mutations in $W / W^{V}$ mice affect the function of the c-kit/W gene product rather than its expression. The individual contributions of the $W$ and the $W^{V}$ alleles to these observations cannot be assessed at this time and it will therefore be of importance to determine the properties of the c-kit kinase from $W / W$ and $W^{v} / W^{v}$ mast cells.

\section{Discussion}

Genetic and molecular evidence indicated previously that the c-kit proto-oncogene and the $W$ locus are identical (Chabot et al. 1988; Geissler et al. 1988). This con- clusion was based on genetic mapping experiments demonstrating tight linkage between c-kit and $W$ and the observation that the c-kit gene is disrupted in the $W^{44}$ allele. The experiments reported here extend this conclusion as follows. First, expression of the c-kit gene was demonstrated in cell types and cell lineages that are known to be affected by the $W$ mutation. Second, the levels of c-kit RNA transcripts are reduced in livers of $W / W$ homozygous fetuses, and this reduction in c-kit transcripts is associated with a reduction in erythropoiesis and in the number of committed erythroid progenitor cells in these animals. Third, the protein product of the c-kit gene in $W / W^{V}$ mast cells and brain tissue was shown to have an impaired tyrosine kinase activity demonstrated by using the immune complex kinase procedure. Taken together, these data provide strong evidence that the c-kit proto-oncogene and the gene encoded by the $W$ locus are identical and suggest a molecular mechanism for the defect in a $W$ mutation.

Mutations at the $W$ locus occur with a relatively high frequency, indicating a large target for mutagenesis (Russell 1979). This has been taken previously as an indication that the $W$ locus represents a gene cluster; however, the results presented here, as well as those described previously, provide strong evidence that the $W$ locus consists of a single gene, c-kit (Chabot et al. 1988; Geissler et al. 1988). The high frequency of mutation at the $W$ locus, however, might suggest that there are several mechanisms underlying the effects of these mutations.

In some $W$ alleles, hematopoiesis, pigmentation, and fertility are differentially affected, i.e., in $W^{44} / W^{44}$ mice there is a minimal effect on hematopoiesis and $W^{\text {sh }} / W^{\text {sh }}$ mice are fertile (Geissler et al. 1981; Lyon and Glenister 1982). Nonparallel display of mutant characteristics might be the consequence of mutations that affect c-kit transcription or post-transcriptional processing in one and not in another cell type. The 4-kb insertion into an intron of c-kit in the $W^{44}$ allele described by Geissler and co-workers (1988) may well have such effects on c-kit transcription.

However, most often mutations at the $W$ locus affect the three cell lineages to comparable degrees (Geissler et al. 1981). In mutant mice, where $W$ targets are affected similarly, an intrinsic defect of the c-kit receptor is a probable cause of the mutation. There are several aspects of receptor function that might be affected by $W$ mutations, e.g., ligand binding, activation of receptor protein tyrosine kinase, receptor autophosphorylation, ligand-induced receptor internalization, and receptor downregulation (Rosen 1987). In agreement with this prediction, we have demonstrated impaired tyrosine kinase activity of the c-kit protein in mast cells and brain tissue of $W / W^{V}$ mice by using the immune complex kinase procedure. The exact structural basis for the altered kinase activity in $W / W^{V}$ mice, as well as the mechanism by which the $W / W^{V}$ mutations affect c-kit receptor function, are not yet known and remain to be determined. A detailed molecular analysis of $W$ alleles with mutations in the coding region of c-kit promises to be a 


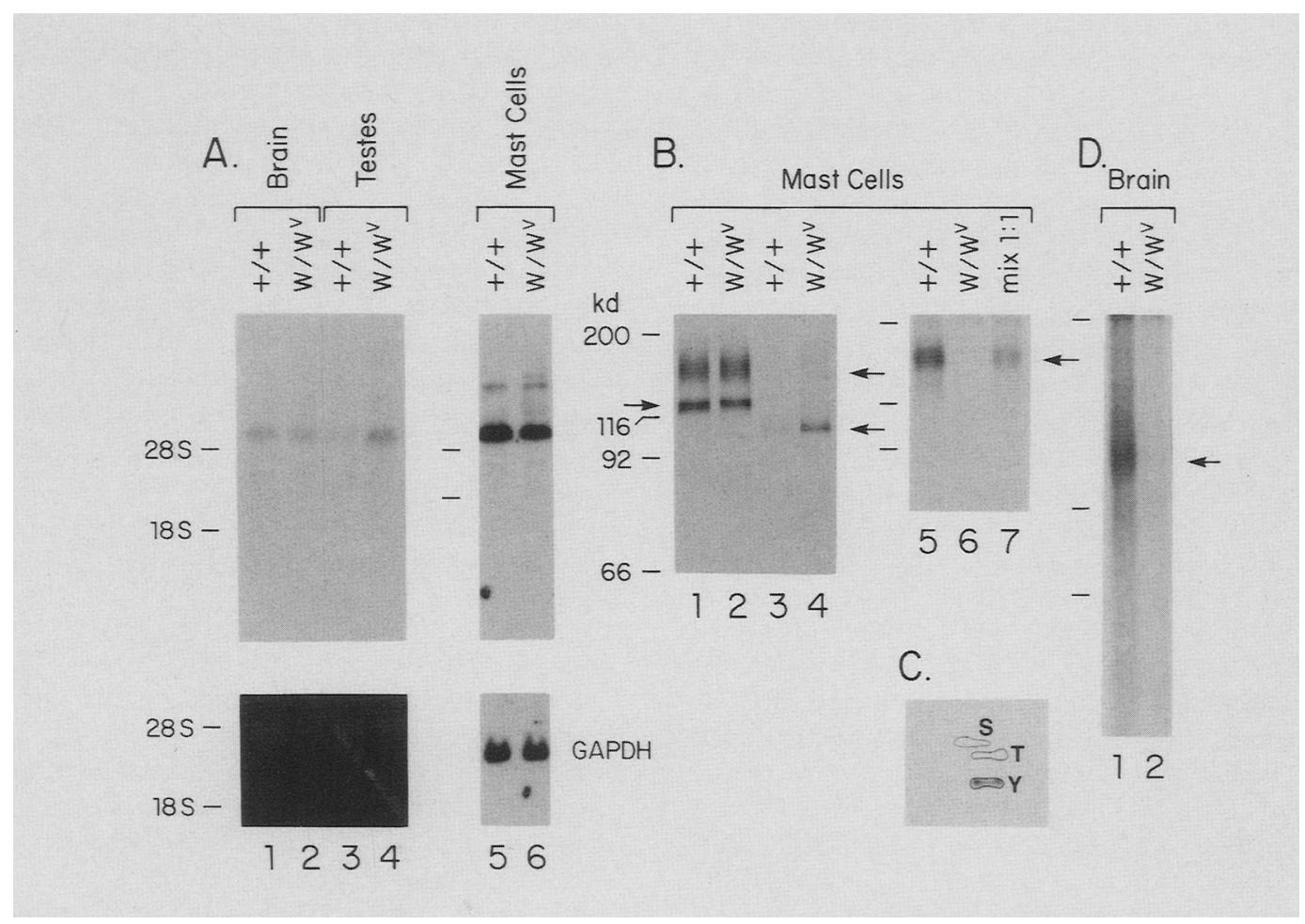

Figure 5. c-kit RNA and protein expression and protein kinase activity in tissues and mast cells of wild type $(+/+)$ and $\left(W / W^{V}\right)$ mice. Tissues and bone marrow cells were obtained from 30 -day-old $\mathrm{WBB}_{6}+1+$ and $W / W^{V}$ male mice. Bone marrow cells were cultured in the presence of WEHI-3 CM for 6 weeks to obtain a population containing $>95 \%$ mast cells. $(A)$ RNA from brain (lanes 1 and 2), testes (lanes 3 and 4), and tissue-culture mast cells (lanes 5 and 6) was analyzed by blot hybridization. Hybridization was done with the c-kit cDNA probe. A probe for GAPDH and 28S and 18S RNA, revealed by ethidium bromide staining, were used as a control for equal loading. $(B) \mathrm{c}$-kit protein in normal and mutant mast cells: Tissue-culture mast cells were labeled for $5 \mathrm{hr}$ with $\left[{ }^{35} \mathrm{~S}\right] \mathrm{methio}-$ nine in the absence (lanes 1 and 2) and presence of tunicamycin $(8 \mu \mathrm{g} / \mathrm{ml}$ ) (lanes 3 and 4). Triton X-100 lysates were prepared, and equivalent amounts of protein were immunoprecipitated with anti-kit serum and analyzed by SDS/PAGE (10\%). Cell lysates prepared from unlabeled mast cells $\left(+/+\right.$, lane $5 ; W / W^{V}$, lane 6 ; and $1: 1$ mixture of $+1+$ and $W / W^{V}$ extracts, lane 7$)$ were immunoprecipitated and processed for autophosphorylation reactions with $\left[\alpha^{-32} \mathrm{P}\right] \mathrm{ATP}$. The reaction products were analyzed by SDS/PAGE $(10 \%)$ and autoradiography. Arrows indicate the relative mobility of c-kit protein products. $(C)$ Phosphoamino acid analysis of the ${ }^{32} \mathrm{P}-\mathrm{labeled}$ $+/+$ c-kit phosphorylation product is shown. Migration of phosphoserine $(\mathrm{S})$, phosphothreonine $(\mathrm{T})$, and phosphotyrosine $(\mathrm{Y})$ markers is indicated. $(D)$ Extracts from brain of $+1+$ and $W / W^{V}$ animals were immunoprecipitated with kit antiserum, processed for autophosphorylation reactions with $\left[\alpha^{32} \mathrm{P}\right] \mathrm{ATP}$, and analyzed by SDS/PAGE $(7.5 \%)$ and autoradiography. Protein size markers are indicated in kilodaltons.

powerful approach for studying structure-function relationships of tyrosine kinase transmembrane receptors and will provide an understanding of how structural mutations in a receptor kinase affect signal transduction, cell proliferation, differentiation, and development.

Characteristically, the defect of $W$ mutations is intrinsic to the affected cells, and it seemed plausible that the cellular targets of these mutations would express $\mathrm{c}$-kit. Our studies have addressed this question for selected cell types of the hematopoietic and the pigment cell lineages. The skin of mice with $W$ mutations is depleted of tissue mast cells. In this regard, transplantation experiments by Kitamura and Go (1978) showed that $W / W^{V}$ skin is repopulated with mast cells when grafted onto mast-cell-deficient $S I / S I^{d}$ mice. One interpretation of this result is that the skin provides microenvironmental factors that facilitate the differentiation and maturation of mast cells in the skin, and by inference this suggested that mast cells might express c-kit. The high level of expression of c-kit seen in mast cell lines and in bone-marrow-derived tissue-culture mast cells (BMMCs), suggests an important role for c-kit in these cells. BMMCs are thought to be precursors of tissue mast cells (Tertian et al. 1981; Nakano et al. 1985; LeviSchaffer et al. 1986), and intravenous injection of normal $(+1+)$ BMMCs into mast-cell-deficient $W / W^{V}$ mice results in the repopulation of mast-cell-deficient tissues (Nakano et al. 1985). In contrast, BMMCs from $W / W^{V}$ mice, which can be generated efficiently (Yung and Moore 1982), fail to repopulate tissues with mast cells in $W / W^{v}$ mice. These observations might indicate that the $\mathrm{c}-\mathrm{kit}^{\mathrm{W}}$ mutations block a late stage in the differentiation and maturation of mast cells in mutant mice.

The defects of both melanogenesis and gametogenesis in $W$ mice are thought to be the result of impaired migratory properties of melanoblasts and primordial germ cells during early embryogenesis (Mintz and Russell 1957; Mayer and Green 1968). However, the observation 
of c-kit expression in melanocytes points to a role for $c-k i t$ in the terminal stages of differentiation of melanocytes as well. Taken together, the expression of c-kit in these cell systems indicates a prominent role for c-kit in late stages of hematopoietic cell differentiation and in the terminal stages of melanogenesis.

A target of $W$ mutations of great biological significance are stem cells: pluripotential hematopoietic stem cells, primordial germ cells, and neural-crest-derived pigment stem cells. In these systems, $W$ appears to affect cell migration and cell proliferation (Mintz and Russell 1957; Mayer and Green 1968; MuCulloch et al. 1964). All of these cells are difficult to obtain or are small in number. In addressing this issue, we have analyzed the hematopoietic stem cell line FDCP-mix and found a very low level of c-kit expression (Spooncer et al. 1985, 1986). Clearly, more extensive studies are needed to firmly establish expression and function of c-kit in primitive hematopoietic stem cells.

Most $W$ mutations cause macrocytic anemia and are known to affect the erythroid progenitors BFU-E and CFU-E, suggesting that there is expression of c-kit in the erythroid cell lineage (Gregory and Eaves 1978; Iscove 1978b; Russell 1979). In agreement with this prediction, c-kit expression was found to concur with sites of active hematopoiesis/erythropoiesis in fetal liver, adult bone marrow, as well as in F-MuLV (SFFV)-transformed cell lines. In addition, c-kit expression in $W / W$ fetal livers was found to be depressed, presumably because of a reduction of c-kit-expressing erythroid cell populations in the fetal liver as a result of the mutation. In this regard, it was of interest to analyze hematopoietic progenitor cell populations in $W / W$ fetal livers. The data on erythroid progenitors indicated that the $W / W$ fetal livers contained wild-type levels of BFU-E, whereas the levels of the more mature CFU-E were markedly reduced. Normal numbers of the granulocyte-macrophage progenitor cells (GM-CFC) were observed in $W / W$ fetal liver consistent with earlier observations of only minor effects on granulopoiesis in $W$ mutant mice (Russell 1979). These observations are consistent with a previous report indicating that following hypertransfusion of adult mice, CFU-E, and not BFU-E, were substantially more affected in adult $W / W^{V}$ mice, relative to their $+1+$ littermates (Gregory et al. 1974). In contrast, in the bone marrow and the spleen of adult $W / W^{V}$ mice, the number of both BFU-E and CFU-E had been found to be diminished but to different degrees (Gregory and Eaves 1978; Iscove 1978b). Apparently, because of the differing microenvironments in fetal liver, adult spleen, and bone marrow, $W$ mutations affect erythropoiesis to different degrees and at different stages of differentiation in the various hematopoietic organs.

A picture that appears to emerge for proto-oncogene $c-k i t$ function suggests a role for c-kit in several cell lineages, including the hematopoietic system, pigment cells, and germ cells. In all these cell lineages, c-kit may function as a receptor for an as yet unidentified extracellular ligand at the stem cell level, as well as in progressively more mature cell populations, and thus may pro- vide cell proliferation and differentiation signals along distinct differentiation pathways. Synergism of the c-kit ligand with other growth and differentiation factors may provide mechanisms for the various modes of c-kit-mediated differentiation. An example of this kind of synergism is seen with CSF-1 and the multilineage factors, interleukin-1 and interleukin-3, where primitive cells are stimulated to proliferate and differentiate into more mature mononuclear cells with a concomitant increase of CSF-1 receptors (Bartelmez and Stanley 1985; Koike et al. 1986). Mutation at the $W$ locus then might affect various stages of differentiation along a developmental pathway, depending on whether other synergistic factors are present or not.

Mammalian transmembrane protein tyrosine kinase receptors have prominent roles in signaling mechanisms involved in cell proliferation and other cellular processes. The finding that the pleiotropic developmental defects in $W$ mutant mice are the result of an impaired transmembrane protein tyrosine kinase provides evidence that receptor protein tyrosine kinases have important roles in complex mammalian developmental processes.

\section{Experimental procedures}

\section{Mice and embryo identification}

NFS/n mice were obtained from Dr. P.V. O'Donnell (SKI) and maintained in our own colony by brother/sister mating. WBB6 $+/+$ and $W / W^{V}$ mice were purchased from the Jackson Laboratory (Bar Harbor, Maine). WB/Re $W /+$ animals were mated and examined daily for the presence of vaginal plugs to determine the age of embryos. Upon the detection of a vaginal plug, the female was isolated and sacrificed 14-16 days later by cervical dislocation; embryos were removed and placed in physiological saline, and tissues from each fetus handled individually. Of the expected progeny, only $W / W$ embryos were identified by their characteristic lighter color and the smaller and paler appearance of their liver. In one experiment, the genotype was confirmed by injecting $10^{3}$ fetal liver cells into irradiated $+/+$ animals and scoring CFU-S (McCulloch et al. 1964).

\section{Progenitor cell assays}

Individual fetal livers were dissected free in Iscove's modified Dulbecco's medium (IMDM) and disaggregated into single-cell suspension by passage through a hypodermic needle ( 23 gauge). Cells $\left(10^{5}\right)$ from each fetal liver were plated in duplicate in IMDM containing $1 \%$ methylcellulose (Fluka), $1 \mathrm{U} / \mathrm{ml}$ erythropoietin, 10\% WEHI-3B conditioned medium, 10\% 5637 conditioned medium, and $30 \%$ fetal calf serum. Colony formation was monitored at appropriate times $(2-3$ days for CFU-E and 7-10 days for BFU-E/GM-CFC) (Iscove 1978a).

\section{Tissues and cell lines}

Tissues were removed from $\mathrm{NFS}, \mathrm{WBB}_{6}+1+$, and $W / W^{V}$ mice, 6-8 weeks of age, and frozen on dry ice. Mast cell cultures were grown from bone marrow cells of $+1+$ and $W / W^{V}$ mice in RPMI-1640 medium supplemented with $10 \%$ fetal calf serum, $10 \%$ conditioned medium from WEHI-3B D-cells, nonessential amino acids, and sodium pyruvate (Yung and Moore 1982). 
After the first 2 weeks of culture, nonadherent cells were harvested from flasks, refed biweekly, and maintained at a cell density of $<7 \times 10^{5}$ cells $/ \mathrm{ml}$. The myeloid cell lines examined included WEHI-3B D ${ }^{+}$, WEHI-3B D- (Ralph et al. 1976), 32D (Greenberger et al. 1983), and M1 (Ichikawa 1969). The P815 mast cell line (Ralph et al. 1976) and the IL-3-dependent mast cell line MC were obtained from Y.P. Yung (Amgen Corp.), murine melanocyte and Cloudman melanoma cell lines from $\mathbf{R}$. Halaban (Yale), MEL cells from M. Sheffery (Marks and Rifkind 1978), and the erythroid cell lines DP-15, DP-20, DP-27, DP-28, and CB-7 were established as published previously (Shibuya and Mak 1983; Mowat et al. 1985). The murine hematopoietic stem cell line FDCP-mix clone A4 was provided by T.M. Dexter (Spooncer et al. 1985). The lymphoid T-cell lines CTLL (Gillis et al. 1978), RBL-5 (Kaminsky et al. 1983), and the AKR thymoma-derived lines BW 5147, CK4, CK6, and 69L1 were obtained from Paul O'Donnell. RNA samples from the monocytic/macrophage cell lines RAW 264.7 (Raschke et al. 1978), J774 (Ralph et al. 1975) and P388Dl (Koren et al. 1975) were obtained from J. Ravetch; from the B-cell precursor cell lines BASC6.C2, HAFTL-1 (Holmes et al. 1986), 22D6P, and 30019P from F. Alt and N. Rosenberg; and from the mature B-cell lines 6D5, d3-1-1, G2-1, Al05, C11, d3-2-1, d1-5-1, Pre 3-9. Pre 3-6, and d0-7-2 from N. Rosenberg (Waneck and Rosenberg 1981, Reth and Alt 1984; Serunian and Rosenberg 1986).

\section{Preparation and analysis of RNA}

Frozen tissues were homogenized in guanidinium isothiocyanate and RNA isolated by centrifugation through $\mathrm{CsCl}$ according to the method of Chirgwin (Chirgwin et al. 1979). Total cellular RNA (10-15 $\mu \mathrm{g})$ was fractionated in $0.7 \%$ agaroseformaldehyde gels and transferred to nylon membranes $/ \mathrm{Ny}$ tran, Schleicher and Schuell), and prehybridization and hybridization was performed as described previously (Lehrach et al. 1977; Besmer et al. 1983). The final wash of hybridized filters was in $0.3 \times$ SSC $[1 \times$ SSC: $150 \mathrm{mM} \mathrm{NaCl}, 15 \mathrm{~mm} \mathrm{Na}$ citrate $(\mathrm{pH} 7.0)]$, and $0.2 \%$ SDS at $65^{\circ} \mathrm{C}$. The murine $5.1-\mathrm{kb}$ c-kit cDNA labeled with $\left[{ }^{32} \mathrm{P}\right]$ phosphate, prepared by the random primer methods, was used as a probe for hybridization (Feinberg and Vogelstein 1983). The amount of RNA in each sample was assessed by hybridization with a GAPDH probe or by comparing the $28 \mathrm{~S}$ and $18 \mathrm{~S}$ rRNAs in the gel visualized by ethidium bromide.

\section{Immunoprecipitation and autophosphorylation of $c$-kit protein}

For metabolic labeling, subconfluent cultures of melanocytes, $\mathrm{NH}$-ck cells, and mast cells were washed with PBS and incubated in methionine-free culture medium without serum for 60 $\min$ at $37^{\circ} \mathrm{C}$. Methionine labeled with ${ }^{35} \mathrm{~S}(200 \mu \mathrm{Ci} / \mathrm{ml})$ was added, and incubation continued for 2 or $5 \mathrm{hr}$. In some experiments, tunicamycin $(8 \mu \mathrm{g} / \mathrm{ml}$, Calbiochem) was added during the labeling period. The cells were washed three times in icecold PBS and lysed in buffer containing $1 \%$ Triton X-100, 20 $\mathrm{mm}$ Tris (pH 7.4), $150 \mathrm{~mm} \mathrm{NaCl}, 20 \mathrm{mM}$ EDTA, and the protease inhibitors phenylmethyl sulfonylchloride (1 $\mathrm{mM})$ and leupeptin $(20 \mu \mathrm{g} / \mathrm{ml})$ (Kris et al. 1985). Extracts were clarified by centrifugation in an Eppendorf centrifuge. Equal amounts of protein (TCA precipitable counts) were immunoprecipitated by incubation with preimmune or anti-kit rabbit antisera conjugated to protein A-Sepharose beads (Pharmacia) for $90 \mathrm{~min}$ at $4^{\circ} \mathrm{C}$. Immunoprecipitates were washed once at $4^{\circ} \mathrm{C}$ in $50 \mathrm{~mm}$ Tris, $500 \mathrm{~mm} \mathrm{NaCl}, 5 \mathrm{~mm}$ EDTA, $0.2 \%$ Triton X-100, three times in $50 \mathrm{~mm}$ Tris, $150 \mathrm{~mm} \mathrm{NaCl}, 5 \mathrm{~mm}$ EDTA, $0.1 \%$ Triton $\mathrm{X}-100,0.1 \%$ SDS, and once in $10 \mathrm{~mm}$ Tris, $01 \%$ Triton $\mathrm{X}-100$ and resuspended in SDS/gel sample buffer $[62.5 \mathrm{mM}$ Tris $1 \mathrm{pH}$ 6.8 ), $2 \%$ SDS, $2 \%$ mercaptoethanol, $10 \%$ glycerol], boiled for 5 min, and analyzed by SDS/PAGE and autoradiography.

Immune complex kinase assay was performed essentially as described previously (Majumder et al. 1988). Mast cells $\left(2 \times 10^{6}\right.$ to $5 \times 10^{6}$ ) were homogenized in $50 \mathrm{mM}$ HEPES, $150 \mathrm{~mm} \mathrm{NaCl}$, $1 \%$ Triton X-100, $10 \%$ glycerol, $1 \mathrm{mM}$ PMSF, and $20 \mu \mathrm{g} / \mathrm{ml} \mathrm{leu-}$ peptin (HNTG lysis buffer) and clarified at $100,000 \mathrm{~g}$ for $45 \mathrm{~min}$. For immunoprecipitation, equal amounts of protein (determined by the Bio-Rad protein assay) were precleared with preimmune rabbit serum-coated protein $\mathrm{A}-$ Sepharose and then precipitated with anti-kit2 coated protein A-Sepharose for 90 $\min$ at $4^{\circ} \mathrm{C}$. Immunoprecipitates were washed as described, and the washed pellets incubated in $30 \mu 1$ of $10 \mathrm{~mm}$ PIPES (pH 7.2), $10 \mathrm{mM} \mathrm{MnCl} 2,10 \mu \mathrm{M} \mathrm{ATP}, 20 \mu \mathrm{M}$ sodium vanadate, and $20 \mu \mathrm{Ci}$ $\left[\alpha^{-32} \mathrm{P}\right]$ ATP for $10 \mathrm{~min}$ at $30^{\circ} \mathrm{C}$. In addition, the immune complex kinase assays were performed according to an alternative published procedure (Kris et al. 1985). The determination of c-kit kinase activity in immune complexes from wheat germ agglutinin-purified brain extracts was carried out as described (Majumder et al. 1988). The reaction products were analyzed by SDS/PAGE and autoradiography. Phosphoamino acid analysis was carried out as described previously (Cooper et al. 1983; Majumder et al. 1988).

\section{Acknowledgments}

We thank Drs. Naomi Rosenberg, Michael Dexter, Janet Hartley, Ruth Halaban, Fred Alt, Mike Sheffrey, Jeff Ravetch, Stuart Macphail, and Cliff Hume for cell lines and tumor and RNA samples. We are grateful to Dr. Malcolm Moore for his comments on this manuscript, as well as his inspiring discussions about $W$. We acknowledge Dr. Ora Rosen and the Viral Oncology Group for their advice, continued interest, and discussions. This work was supported by grants from the American Cancer Society (MV-246B) to P.B., from the National Cancer Institute (CA-32926) to P.B., and from the National Cancer Institute of Canada to A.B. B.C. was a research fellow of the NCIC.

\section{References}

Barker, J.E. and E.C. McFarland. 1988. Hemopoietic precursor cell defects in nonanemic but stem cell-deficient W44/W44 mice. J. Cell. Physiol. 135: 533-538.

Bartelmez, S.H. and E.R. Stanley. 1985. Synergism between hemopoietic growth factors (HGFs) detected by their effects on cells bearing receptors for a lineage specific HGF: Assay of hemopoietin-1. I. Cell. Physiol. 122: 370-378.

Besmer, P., H.W. Snyder, J.E. Murphy, W.D. Hardy, and A Parodi. 1983. The Parodi-Irgens feline sarcoma virus and simian sarcoma virus have homologous oncogenes, but in different contexts of the viral genomes. J. Virol. 46: 606613.

Besmer, P., P.C. Murhpy, P.C. George, F. Qui, P.J. Bergold, L. Lederman, H.W. Snyder, D. Brodeur, E.E. Zuckerman, and W.D. Hardy. 1986. A new acute transforming feline retrovirus and relationship of its oncogene v-kit with the protein kinase gene family. Nature 320: 415-421.

Chabot, B., D.A. Stephenson, V.M. Chapman, P. Besmer, and A. Bernstein. 1988. The proto-oncogene c-kit encoding a transmembrane tyrosine kinase receptor maps to the mouse $\mathrm{W}$ locus. Nature 335: 88-89.

Chirgwin, J.M., A.E. Przbyla, J.R. Macdonald, and W.J. Rutter. 1979. Isolation of biologically active ribonucleic acid from 
sources enriched in ribonuclease. Biochemistry 18: 52945299.

Cooper, J.A., B.M. Sefton, and T. Hunter. 1983. Detection and quantification of phosphotyrosine in proteins. Methods Enzymol. 99: 387-402.

deAeberle, S. 1927. A study of hereditary anemia in mice. Am. J. Anat. 40: 219-247.

Feinberg, A.P. and B. Vogelstein. 1983. A technique for radiolabeling DNA restriction fragments to high specific activity. Ann. Biochem. 132: 6-13.

Geissler, E.N., M.A. Ryan, and D.E. Housman. 1988. The dominant-white spotting (W) locus of the mouse encodes the c-kit proto-oncogene. Cell 55: 185-192.

Geissler, E.N., E.C. McFarland, and E.S. Russell. 1981. Analysis of pleiotropism at the dominant white-spotting (W) locus of the house mouse: A description of ten new W alleles. $\mathrm{Ge}$ netics 97: 337-361.

Gillis, S., M.M. Ferm, W. Ou, and K.A. Smith. 1978. T cell growth factor: Parameters of production and a quantitative microassay for activity. I. Immunol. 120: 2027-2032.

Greenberger, J.S., M.A. Sakakeeny, R.K. Humphries, C.J. Eaves, and R.J. Eckner. 1983. Demonstration of permanent factordependent multipotential (erythroid/neutrophil/basophil) hematopoietic progenitor cell lines. Proc. Natl. Acad. Sci. 80: $2931-2935$.

Gregory, C.J. and A.C. Eaves. 1978. Three stages of erythropoietic progenitor cell differentiation distinguished by a number of physical and biologic properties. Blood 51: 527537.

Gregory, C.J., A.D. Tepperman, E.A. McCulloch, and J.E. Till. 1974. Erythropoietic progenitors capable of colony formation in culture: Responses of normal and genetically anemic $\mathrm{W} / \mathrm{Wv}$ mice to manipulations of the erythron. I. Cell. Physiol. 840: 1-12.

Harrison, D.E. 1980. Competitive repopulation: A new assay for long-term stem cell functional capacity. Blood 55: 7781 .

Holmes, K.L., J.H. Pierce, W.F. Davidson, and H.C. Morse. 1986. Murine hematopoietic cells preB or pre-B/myeloid characteristics are generated by in vitro transformation with retroviruses containing fes, ras, abl and src oncogenes. $J$. Exp. Med. 164: 443-457.

Ichikawa, Y. 1969. Differentiation of a cell line of myeloid leukemia. I. Cell. Physiol. 74: 223-231.

Iscove, N.N. 1978a. Erythropoietin independent stimulation of early erythropoiesis in adult marrow cultures by conditioned media from lectin-stimulated mouse spleen cells. In Hematopoietic cell differentiation (ed. D.W. Golde, M.J. Cline, D. Metcalf, and F.C. Fox), pp. 37-52. Academic Press, New York.

Iscove, N.N. 1978b. Committed eythroid precursor populations in genetically anemic $\mathrm{W} / \mathrm{Wv}$ and Sl/Sld mice. In Aplastic anemia (ed. S. Hibino, S. Takaku, and N.T. Shahidi), pp. 31-36. University of Tokyo Press, Tokyo.

Kaminsky, S.G., I. Nakamura, and G. Cudkowicz. 1983. Selective defect of natural killer and killer cell activity against lymphomas in SJL mice: Low responsiveness to interferon inducers. I. Immunol. 130: 1980-1984.

Kitamura, Y. and S. Go. 1978. Decreased production of mast cells in Sl/Sld anemic mice. Blood 53: 492-497.

Koike, K., E.R. Stanley, J.N. Ihle, and M. Ogawa. 1986. Macrophage colony formation supported by purified CSF-1 and/or interleukin 3 in serum-free culture: Evidence for hierarchical difference in macrophage colony-forming cells. Blood 67: 859-864.

Koren, H.S., B.S. Handwerger, and J.R. Wunderlich. 1975. Iden- tification of macrophage-like characteristics in a cultured murine tumor line. J. Immunol. 114: 894-897.

Kris, R.M., I. Lax, W. Gullick, M.D. Waterfield, A. Ullrich, M. Fridkin, and J. Schlessinger. 1985. Antibodies against a synthetic peptide as a probe for the kinase activity of the avian EGF receptor and v-erbB protein. Cell 40: 619-625.

Lehrach, H., D. Diamond, J.M. Wozney, H. Boedtker. 1977. RNA molecular weight determinations by gel electrophoresis under denaturing conditions, a critical reexamination. Biochemistry 16: 4743.

Levi-Schaffer, F., K.F. Austen, P.M. Gravallese, and R.L. Stevens. 1986. Coculture of interleukin 3-dependent mouse mast cells with fibroblasts results in a phenotypic change of the mast cells. Proc. Natl. Acad. Sci. 83: 6485-6488.

Little, C.C. 1915. The inheritance of black-eyed white spotting in mice. Am. Nat. 49: 727-740.

Lyon, M.F. and P.H. Glenister. 1982. A new allele sash (Wsh) at the $\mathrm{W}$-locus and a spontaneous recessive lethal in mice. Genet. Res. 39: 315-322.

Majumder, S., K. Brown, F.-H. Qui, and P. Besmer. 1988. c-kit protein, a transmembranekinase: Identification in tissues and characterization. Mol. Cell. Biol. 8: 4896-4903.

Marks, P.A. and R.A. Rifkind. 1978. Erythroleukemic differentiation. Annu. Rev. Biochem. 47: 419-448.

Mayer, T.C. and M.C. Green. 1968. An experimental analysis of the pigment defect caused by mutations at the $\mathrm{W}$ and $\mathrm{Sl}$ loci in mice. Dev. Biol. 18: 62-75.

McCulloch, E.A., L. Siminovitch, and J.E. Till. 1964. Spleencolony formation in anemic mice of genotype $W / W^{V}$. Science 144: 844-846.

Mintz, B. and E.S. Russell. 1957. Gene induced embryological modifications of primordial germ cells in the mouse. J. Exp. Zool. 134: 207-237.

Moore, M.A.S. and D. Metcalf. 1970. Ontogeny of the hematopoietic system: Yolk sac origin. Br. I. Hematol. 18: 279296.

Mowat, M., A. Cheng, N. Kimura, A. Bernstein, and S. Benchimol. 1985. Rearrangements of the cellular p53 gene in erythroleukemic cells transformed by Friend virus. Nature 314: 633-636.

Nakano, T., T. Sonoda, C. Hayashi, A. Yamatodani, Y. Kanayama, T. Yamamura, H. Asai, T. Yonezawa, Y. Kitamura, and S.J. Galli. 1985. Fate of bone marrow-derived mast cells after intracutaneous, intraperitoneal and intravenous transfer into genetically mast cell deficient $\mathrm{W} / \mathrm{Wv}$ mice: Evidence that cultures mast cells can give rise to both connective tissue-type and mucosal mast cells. I. Exp. Med. 162: 1025-1043.

Qiu, F., P. Ray, K. Brown, P.E. Barker, S. Jhanwar, R.H. Ruddle, and P. Besmer. 1988. Primary structure of c-kit: Relationship with the CSF-1/PDGF receptor kinase family-Oncogenic activation of v-kit involves deletion of extracellular domain and c-terminus. EMBO J. 7: 1003-1011

Ralph, P., M.A.S. Moore, and K. Nilsson. 1976. Lysozyme synthesis by established human and murine histiocytic lymphoma cell lines. J. Exp. Med. 143: 1528-1533.

Ralph, P., J. Prichard, and M. Cohn. 1975. Reticulum cell sarcoma: An effector cell line in antibody-dependent cell-mediated immunity. I. Immunol. 114: 898-905.

Raschke, W.C., S. Baird, P. Ralph, and I. Nakoinz. 1978. Functional macrophage cell lines transformed by Abelson leukemia virus. Cell 15: 261-267.

Reth, M.G. and F.W. Alt. 1984. Novel immunoglobulin heavy chains are produced from $\mathrm{DJH}$ gene segment rearrangements in lymphoid cells. Nature 312: 418-423. 
Nocka et al.

Rosen, O.M. 1987. After insulin binds. Science 237: 14521458.

Russell, E.S. 1970. Abnormalities of erythropoiesis associated with mutant genes in mice. In Regulation of hematopoiesis, (ed. A.S. Gordon), pp. 649-675. Appleton, New York.

. 1979. Hereditary anemias of the mouse: A review for geneticists. Adv. Gen. 20: 357-459.

Russell, E.S. and S.E. Bernstein. 1968. Proof of whole cell implant in therapy of $\mathrm{W}$ series of anemia. Arch. Biochem. Biophys. 125: 594-597.

Serunian, L.A. and N. Rosenberg. 1986. Abelson virus potentiates long-term growth of mature B lymphocytes. Mol. Cell. Biol. 6: 183-194.

Shibuya, T. and T.W. Mak. 1983. Isolation and induction of erythroleukemic cell lines with properties of erythroid progenitor burst-forming cell (BFU-E) and erythroid precursor cell (CFU-E). Proc. Natl. Acad. Sci. 80: 3721-3725.

Silvers, W.K. 1979. White-spotting, patch and rump-white. In The coat colors of mice: $A$ model for gene action and interaction. pp. 206-241. Springer-Verlag, New York.

Spooncer, E., D. Boettiger, and T.M. Dexter. 1985. Continuous in vitro generation of multipotential stem cell clones from src-infected cultures. Nature 310: 228-230.

Spooncer, E., C.M. Heyworth, A. Dunn, and T.M. Dexter. 1986. Self-renewal and differentiation of interleukin-3-dependent multipotent stem cells are modulated by stromal cells and serum factors. Differentiation 31: 111-118.

Tamura, A., R. Halaban, G. Moellmann, J.M. Cowan, M.R. Lerner, and A.B. Lerner. 1987. Normal murine melanocytes in culture. In Vitro 23: 519-522.

Tertian, G., Y.P. Yung, D. Guy-Grand, and M.A.S. Moore. 1981. Long-term in vitro culture of murine mast cells I. Description of a growth factor-dependent culture technique. J. Immunol. 127: 788-794.

Waneck, G. and N. Rosenberg. 1981. Abelson leukemia virus induces lymphoid and erythroid colonies in infected fetal cell cultures. Cell 26: 79-89.

Yarden, Y., W.J. Kuang, T. Yang-Feng, L. Coussens, S. Munemitsu, T.J. Dull, E. Chen, J. Schlessinger, U. Francke, and A. Ullrich. 1987. Human proto-oncogene c-kit: A new cell surface receptor tyrosine kinase for an unidentified ligand. $E M B O$ /. 6: 3341-3351.

Yung, Y.P. and M.A.S. Moore. 1982. Long-term in vitro culture of murine mast cells III. Discrimination of mast cell growth factor and granulocyte-CSF. I. Immunol. 129: 1256-1261. 


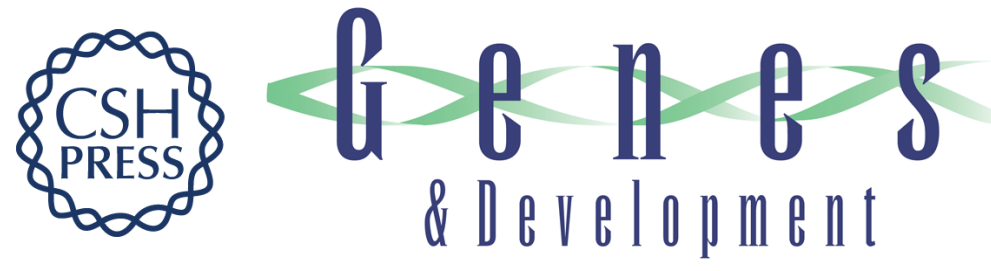

\section{Expression of c-kit gene products in known cellular targets of W mutations in normal and W mutant mice--evidence for an impaired c-kit kinase in mutant mice.}

K Nocka, S Majumder, B Chabot, et al.

Genes Dev. 1989, 3:

Access the most recent version at doi:10.1101/gad.3.6.816

References This article cites 52 articles, 21 of which can be accessed free at: http://genesdev.cshlp.org/content/3/6/816.full.html\#ref-list-1

License

Email Alerting Service

Receive free email alerts when new articles cite this article - sign up in the box at the top right corner of the article or click here.

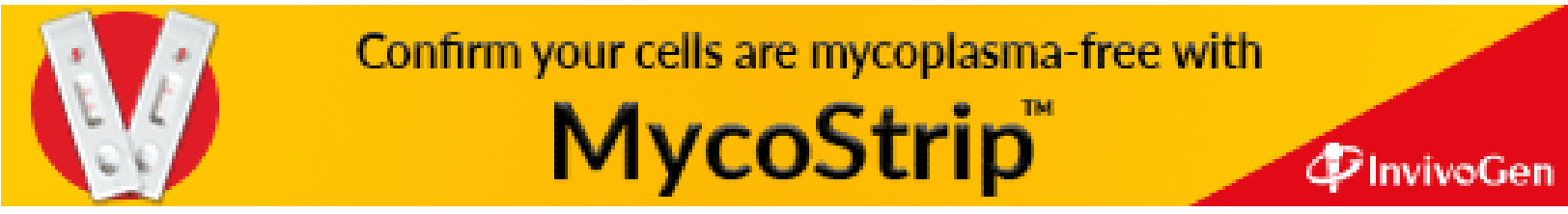

